The Quarterly Journal of Austrian Economics

Volume 23 | NO. 1 | 46-66 | SpRING 2020

WWW.QJAE.ORG

\title{
Beyond Calculation: The Austrian Business Cycle in the Socialist Commonwealth
}

\author{
Mark A. DeWeaver*
}

JEL Classification: B51, B53, E32, P21, P51

Aвstract: This paper extends Austrian business cycle theory to the command economy and demonstrates that Mises's socialist commonwealth would not be free from Rothbardian error cycles, which J. Guido Hülsmann has argued must originate in "institutions in which the error of many persons is inherent." Booms and busts are shown to be unavoidable under socialism because (1) the central planner's incomplete understanding of the opportunity costs associated with any given rate of growth would result in growth targets that are unsustainably high and (2) the planner would be blind to the resulting imbalances until they became sufficiently severe to become "visible" in the statistical data that form her only picture of the world. In this case, Hülsmann's "erroneous institution" is central planning, which misidentifies the state's image of the economy with the totality of economic reality.

"Economic construction proceeds in wave-like fashion with its ups and downs, and one wave chasing another. This is to say that there are balance, disruption, and balance restored after disruption." -Mao Zedong (1959)

\footnotetext{
"Mark A. DeWeaver (madeweaver@gmail.com) is an adjunct professor at American University's Kogod School of Business and cofounder of the fund management company Ithaca Advisors, LLC. The author would like to thank the participants at the 2019 Libertarian Scholars Conference and an anonymous referee for their helpful comments and suggestions.
} 
$T^{t}$ is often supposed that business cycles would not occur under central planning. Indeed, in most business cycle models a central planner should be able to improve upon the "anarchy of the market." Keynes's ([1936] 1997) animal spirits could be eliminated, the adaptive expectations of Samuelson's (1939) accelerator/multiplier model could be replaced by a rational program, the planner's supposed informational advantages would solve the incomplete information problem in the Lucas (1972) rational expectations story, and, in the absence of the "exploitation" of labor by capital, Marx's ([1863] n.d., chapter XVII, part 6) "crises of accumulation" would not occur.

Although most business cycle theorists have not explicitly advocated central planning, explanations based on the limitations of private actors can easily be misinterpreted as implying that eliminating market forces would be an improvement. Keynes ([1936] 1997, 320) makes this claim explicitly, arguing that "the duty of ordering the current volume of investment cannot safely be left in private hands." Here the implicit assumption is that the state official will behave more rationally than the businessperson, a view entirely consonant with Keynes's lifelong advocacy of socialist policies (Fuller 2019). His argument is a good example of what Demsetz (1969) calls the "nirvana approach" — a case for state intervention made by contrasting real-world free market outcomes with what an ideal government could achieve in a "first best" world. Keynes is essentially saying that a system directed by angels would be preferable to one run by fallible human beings.

In the Austrian tradition the planner tends to be seen as demonic rather than angelic. Here too, however, we find claims that central planning would not generate economic fluctuations. In Human Action, for example, Ludwig von Mises ([1949] 1998) argues that the periodic crises experienced in free enterprise economies, which he attributes to incompatibilities among the plans of different economic actors, would not occur under socialism, which would allow for only one plan - that of the dictator. "If the dictator invests more and thus curtails the means available for current consumption," he writes, "the people must eat less and hold their tongues. No crisis emerges because the subjects have no opportunity to utter their dissatisfaction" (566). Although rational decision-making would be impossible in his socialist commonwealth, there would at least be no booms and busts. 
Similarly, for Huerta de Soto (2006) the claim that "an economy of real socialism offers the advantage of eliminating economic crises is tantamount to affirming that the advantage of being dead is immunity to disease." If cycles are not observed in socialist countries, this is not the mark of a superior system but rather a sign that they are "are continually and permanently in a situation of crisis and recession" (472-73).

Yet the economic history of socialist countries includes boom-bust episodes that in many cases have been even more extreme than those observed elsewhere. Kornai's (1992) classic study of the Soviet Union and Eastern Europe found that "while some socialist economies grow relatively smoothly, others show wild fluctuations, even larger ones than in many capitalist countries" (187). He noted that the coefficients of variation for annual investment growth in Yugoslavia, Poland, and Hungary were 278 percent, 187 percent, and 171 percent, respectively, all higher than those for the $\neg$ capitalist countries in his sample, which covers the period from 1960 to 1989. (Of these, Ireland had the highest value, at 159 percent.) Similarly, the Chinese economy has experienced dramatic cycles in fixed asset investment going back to the Great Leap Forward in 1958 (Eckstein 1976; Fan and Zhang 2004; Wang 2008; DeWeaver 2012).

Research on Soviet-type economies has generally attributed cyclical fluctuations to inconsistencies in the central plan. Wellisz $(1964,233)$, for example, describes the plan as being "fitted together like a jig-saw puzzle," where "an individual piece cannot be trimmed or replaced without spoiling the whole picture." This meant that "a weakness is tolerated as long as possible in order to avoid rearrangement of all the pieces. Finally, when the situation becomes unbearable, radical steps are taken to remedy it. Thus, the economy proceeds by starts and jolts, with successive drives or campaigns to eliminate this or that mistake."

Winiecki (1988) shows how this state of affairs resulted from enterprises' efforts to have their projects included in the five-year plan (FYP) by exaggerating the projected benefits and underestimating the costs. "In consequence," he finds, "the FYP typically starts with significant built-in distortions in its investment component. These distortions exercise, over time, an increased pressure on aggregate equilibrium...shortages multiply and excess demand begins to 
grow." In the majority of cases, the cycle peaked in the second or third year of the plan, at which point the planners "resign themselves to the fact that all planned investment projects will not be completed by the end of the FYP...many projects are 'mothballed', with further construction postponed until the next FYP, and some others discontinued altogether" (1988, 20-21).

In practice, it is evident that central planning has never been an antidote for economic fluctuations. It might still be argued, however, that these historical precedents do not rule out in principle the possibility of a stabilizing role for the planner. If administrative arrangements specific to the countries involved account for the volatility of the socialist economies, perhaps the system might somehow be "perfected," for example by improving the incentives facing enterprise managers and local-level officials. Under ideal conditions, socialism without booms and busts might yet be achievable.

Here my objective is to show that this is not the case. I extend Austrian business cycle theory to the command economy by showing that malinvestment will still occur under central planning whenever any form of economic growth is prioritized. The model, which combines Friedrich Hayek's (1945) insights on the importance of local knowledge with Scott's (1998) concept of "legibility," assumes a planning authority with a limited, though time-varying, statistics-based picture of economic conditions. Cycles then correspond to changes in what can be "read" through statistical data. I find that Mises's calculation problem implies not only static but also dynamic inefficiency.

The fundamental issue is the planner's lack of access to local knowledge, which makes comprehensive planning an impossibility regardless of how the plan is formulated. Ideal local-level officials might selflessly follow the leadership's directives in every particular but will find that these are incomplete. Much will still have to be left to the discretion of the "cadre on the spot," as Hayek might have put it, who will have to set aside his local-knowledge advantage to focus on plan fulfillment. Investment fluctuations will be unavoidable, because (1) the planner's incomplete understanding of the opportunity costs associated with any given rate of growth will result in growth targets that are unsustainably high and (2) the planner will 
be blind to the resulting imbalances until they became sufficiently severe to become "visible" at the aggregate level.

Although the institutional setting is different-administratively set targets take the place of monetary expansions-these dynamics are essentially the same as those described in Austrian business cycle theory. In both cases, faulty signaling of society's rate of time preference leads to the misallocation of resources into more roundabout production, resulting in distortions that must inevitably be corrected through an investment slowdown. When shortages become sufficiently severe, the central planner will be forced to restore order through administrative measures much as central banks in today's market economies have to "take away the punch bowl" when faced with rising inflation.

Today, the socialist business cycle is not only of theoretical and historical interest but also of great practical importance. In China the investment cycle continues to be primarily a state-led phenomenon, operating in much the same way as it did in the pre-reform era (DeWeaver 2012). Booms continue to be driven by investment promotion at the local government level while busts result from central government administrative interventions designed to reimpose macroeconomic stability. Although prior to the beginning of the "reform and opening" period in 1978, the Chinese economy's ups and downs had relatively little relevance to the outside world, today they impact everyone from Swiss watchmakers to Zambian copper miners.

The business cycle in the socialist commonwealth can be considered as an example of what Hülsmann (1998), following Rothbard ([1962] 2004, ch. 11), calls an "error cycle." The root cause of any business cycle, he argues, is what he refers to as an "illusion" - an error that is independent of time and place and can therefore give rise to recurring erroneous behavior. In this case, the illusion is built into the very idea of central planning. It is the misidentification of the image of the economy that is visible to the planner with the totality of economic reality.

The remainder of this paper traces the origins of this illusion, demonstrates why it gives rise to booms and busts, and describes how Austrian business cycle theory can be extended to the centrally planned economy to account for these aberrations. Part I shows 
how socialism was built on a denial of the economic significance of local knowledge, which made it possible for theorists to believe in the possibility of an all-seeing planner. Part II presents a model of fluctuations in an ideal socialist commonwealth and demonstrates that these fluctuations can be considered as a subspecies of the Austrian business cycle where state-set output targets play the role of free market interest rates as a signal of society's rate of time preference. In part III, I review Hülsmann's argument and argue that his "essentialist" error-cycle approach is particularly well suited to this case. Part IV concludes.

\section{THE BIRTH OF AN ILLUSION}

The founders of the Soviet system believed that industrial modernization would give rise to the conditions necessary for central planning to work by eliminating the relevance of local knowledge. This idea is implicit in Marx's claim that with advanced factory technology "the motion of the whole system does not proceed from the workman but from the machinery," implying that "a change of persons can take place at any time without an interruption of the work." (Marx [1887] 1999, 285). Standardization and automation would leave Hayek's man on the spot with no particular informational advantages. Anyone could take his place.

Similarly, Engels ([1894] 1975) believed that modern industry had "freed production from restrictions of locality." "Water power," he noted, "was local; steam power is free" (351). Where "knowledge of the particular circumstances of time and place" (Hayek, 1945) would obviously be important for siting a waterpowered mill, replacing water with steam could potentially make an understanding of locality-specific geographic conditions largely irrelevant. Engels expected that it would become possible for any factory to be located practically anywhere as technological progress swept aside the myriad local differences that had formerly constrained economic development and would allow "industry to be distributed over the whole country...on the basis of one single vast plan" (Engels [1894] 1975, 351).

Lenin (1920) later updated this conception, replacing steam with electric power. Capitalism, he claimed, "depends on small-scale 
production and there is only one way of undermining it, to place the economy... on a new technical basis, that of modern large-scale production. Only electricity provides this basis." Hence his famous dictum, "Communism is Soviet power plus the electrification of the whole country."

The backwardness of peasant Russia, he went on, would be transformed by power stations, which would become "strongholds of enlightenment." Electricity would not only light up the night but would also create a manufacturing base free from the idiosyncrasies of traditional economic arrangements. The central planner would not be groping in the dark but able to see clearly. Lenin was aiming at something much more than the electrification of the whole country. He hoped to leverage the rationalizing potential of technology to achieve what Scott (1998) refers to as the "thoroughly legible society," which "eliminates local monopolies of information and creates a kind of national transparency" (78).

There would then be no need for the "new dispositions made every day in the light of circumstances not known the day before" that Hayek $(1945,524)$ argued were essential to the "continuous flow of goods and services." Instead, as Nikolai Bukharin and Evgenii Preobrazhensky claimed in their 1920 book The ABC of Communism, the state will "know in advance how much labor to assign to the various branches of industry, which products are required and how much of each it is necessary to produce; how and where machines must be provided" ([1920, trans. 1922] 2001, chap. 3). Chaotic interactions among privately owned firms would give way to a smoothly functioning state-directed mechanism.

In China, where Bukharin and Preobrazhensky's readers included Mao Zedong, Deng Xiaoping (Wu and Ma 2016, 23), Beijing mayor and Politburo member Peng Zhen, and People's Liberation Army founder Zhu De (Snow 1968, 271, 335), this notion was taken up uncritically by the Chinese Communist Party. It is, for example, the unstated assumption behind the "chessboard strategy" described in the famous 1959 People's Daily editorial "The Whole Country as a Chess Game" [Quan guo yi pan qi]. Written in response to the chaos following the launch of the Great Leap Forward in the previous year, it called for a return to disciplined central planning, likening the national economy to a chessboard, on which the movements of 
each piece must conform to an overall strategy based on the rules of the game. Implicit in this analogy is the idea that it would be possible for economic life to be just as transparent to the planner as a board game is to the players.

In practice, of course, technology has not created anything like the level of national transparency envisaged by any of these authors. The operations of a large-scale factory can no more be reduced to a straightforward set of rules than the techniques of the traditional artisan. Modern forms of communication have not eliminated "knowledge silos" in complex organizations. Computer algorithms seem unlikely ever to penetrate fully the opacity of asset markets.

Innovations may render older categories of economically significant local knowledge obsolete but may be equally likely to create new ones. Consider the case of the defense aerospace industry. There, Gilli and Gilli (2018) note that "the number of components in military platforms has risen dramatically: in the 1930s, a combat aircraft consisted of hundreds of components, a figure that surged into the tens of thousands in the 1950s and to 300,000 in the 2010s." As a result, "the number of potential incompatibilities and vulnerabilities" has increased "geometrically" (150) and "the knowledge related to a given weapon system has become increasingly less codifiable-it has become tacit" (163). Unlike the knowledge required to produce a World War I era biplane, which could to a large extent be derived from a blueprint, the essential knowledge resources behind a platform such as Lockheed-Martin's Joint Strike Fighter are primarily local, residing in the collective memory of an organization and difficult if not impossible to express in any explicit form. From this example it is easy to see that advances in technology can have exactly the opposite effect from that expected by the early socialists, making the workings of the industrial system ever more opaque.

There can thus be no central planning that does not rely on "state simplifications" that are "always some distance from the full reality these abstractions are meant to capture," as Scott $(1998,77)$ puts it. These, he argues, differ from the full reality because they (1) "cover only those aspects of social life that are of official interest," (2) "are nearly always written," implying that nondeclarative knowledge is necessarily left out, and are (3) "typically static," (4) 
"aggregate," and (5) "standardized." In the real world, where the relevance of different types of information is constantly changing and the particular circumstances of time and place continue to be economically relevant, there will unavoidably be significant blind spots in the planner's "synoptic" view.

The problem, as Hayek $(1988,85)$ pointed out, is that "what cannot be known cannot be planned." But even in the absence of an adequate basis for decision-making, plans will still be made. Decisions will be taken based on whatever the central planners can "see" at any particular time as the bureaucracy collectively succumbs to the illusion that this is a complete picture. Policy goals will necessarily be limited to targets for "synoptically observable abstractions" while the unobservable details of their implementation are left to officials at the local level. The extent to which such a system gives rise to booms and busts will thus depend critically on the activities of these lower-level cadres.

\section{BOOMS AND BUSTS UNDER CENTRAL PLANNING}

The local cadre's responsibility for realizing targets for aggregate variables will be economically destabilizing, because he will be incentivized to generate outcomes that the central government can observe but not to take the associated unobservable economic costs into consideration. As a result, resources will be diverted into planned policy priorities at the expense of activities that are not emphasized, or even contemplated, by the plan. There will be chronic contradictions between the needs of the actual economy and the plans of the economic decision-makers.

When increasing economic output is the primary objective, as has generally been the case historically, this may in principle be achieved through either extensive or intensive growth. But only the former (increasing output by using more inputs) falls within the competence of the planner. Intensive growth, which relies on increased productivity, is intrinsically unplannable. It is straightforward to set material targets for specific items (tons of steel, kilometers of railway lines), as was commonly done in the Soviet Union (Davies 1974), or goals for aggregate measures such as provincial or municipal GDP growth, which have been typical in post-reform 
China (Zhou 2004). But similar "state simplifications" (e.g., number of patents issued) do a poor job of incentivizing genuine innovation.

Attempts to transform the "mode of economic growth" in the Soviet Union and, more recently, in China have been notably unsuccessful. In the 1980s, the Soviets adopted the policy of uskorenie (acceleration), "subordinating everything to the aim of making the economy more intensive and achieving higher production outputs with smaller inputs and less resources" (Tikhonov 1981, 24), which was to be facilitated through the "universal introduction of fundamentally new machinery and materials and the large-scale use of highly efficient energy- and material-saving technology" (Tikhonov 1981, 29-30). This produced few breakthroughs. The difficulties can be seen from the experience of the machine-building industry, a top priority sector, where of the three thousand new products introduced in 1986 to satisfy innovation targets, 40 percent were found to have involved "no substantial shifts" in technology (Matosich and Matosich 1988).

Similarly, every Chinese five-year plan since 1981 has emphasized the importance of greater economic efficiency for the country's future development (DeWeaver 2012, chap. 9). Yet levels of excess capacity in industrial sectors such as steel, cement, float glass, and aluminum - to name but a few-have skyrocketed while China's incremental capital-output ratio has been on a steady uptrend since 2007. And although the jury is still out on Beijing's "National Medium- and Long-Term Plan for the Development of Science and Technology (2006-2020)," its goals illustrate the difficulty of transitioning to intensive growth using command economy methods: R\&D expenditure is supposed to increase to 2.5 percent of GDP, reliance on foreign technology must fall to 30 percent, China must reach fifth place globally in number of patent filings, and so on (McGregor 2010).

Given the obvious problems with raising productivity by fiat, the planner will generally find that extensive growth is the only viable option. As she cannot be aware of all of the opportunity costs associated with any given growth rate, she will necessarily set growth-rate objectives (whether for the entire economy or for specific sectors) that are unsustainably high. The cadre on the spot will respond by investing in infrastructure and the manufacturing base. Hitting material targets will require additional fixed assets 
once the existing capital stock is fully employed. Investment drives will also be the surest route to an aggregate output benchmark, both because fixed asset accumulation is itself a part of aggregate output in the period in which it occurs and because it makes it possible to increase output in subsequent periods. Although the cadre might conceivably attempt to introduce local-level productivity enhancements, his first choice will be to mobilize factors of production that he perceives as having an opportunity cost of zero because they are currently employed in activities that lie outside the planner's field of vision.

Murray Rothbard $([1962,1970] 2004,337)$ notes that intertemporal transactions may take the form of either credit extension or the "purchase of producer goods and services." The latter, he points out, are effectively "future goods" because they will be converted into final products in future periods. In the socialist commonwealth, although money and credit may not exist at all, it will be no less true that the employment of producer goods and services constitutes a substitution of future for present output. And in the absence of changes in productivity or in the availability of land and labor, any growth rate set by the planner will imply a specific requirement for additional capital, which will in turn require some particular increase in investment at the expense of consumption.

Thus, under central planning, state-set targets for output increases based on an extensive growth strategy play an analogous role to the interest rate in a free market system. Both are signals of the rate at which society is willing to sacrifice present for future consumption, that is, of its rate of time preference. Prioritizing economic growth under central planning will therefore give rise to the same outcome as artificially lowering interest rates in a credit-based economy: resources will be shifted into more roundabout production processes. Growth targets have essentially the same effect on the cadre on the spot as do interest rate cuts on Hayek's man on the spot. Both skew the investment decision-maker's incentives in favor of subsequent periods, resulting in a mismatch between the aggregate requirements of investment projects and the means available to carry them out.

Alfred Zauberman $(1964,25)$ notes that historically central planners have generally behaved as "managers of a joint stock 
company whose shareholders are future generations." In other words, we may think of them as assigning a discount rate of zero to outcomes occurring at some indefinite date in the future. That Austrian business cycle theory, with its emphasis on faulty signals of society's true rate of time preference, should be applicable to "actually existing socialism" is thus unsurprising.

In both the socialist and free market cases the outcome will be the same: an initial boom that eventually leads to a crisis as the resulting imbalances become unsustainable. Although in a free market such a crisis can be resolved more or less spontaneously, in the absence of price signals a resolution will not be possible until the essential features of the situation at last come clearly into focus for the planner.

Even under central planning a course correction will eventually be possible, because the planner's picture of the world, although always incomplete, will not be unvarying. The presence of widespread problems in parts of the economy that the planner cannot see will eventually manifest itself through the aggregated information that she can see, revealing disruptions such as raw materials shortages, crop failures, power outages, and transportation bottlenecks. At this point, the threat to longer-term economic growth will force the planner's attention to shift from growth targets to the alleviation of shortfalls. Investment plans will have to be cancelled or put on hold as resources are redirected toward previously neglected activities. This will lead to a crisis analogous to those observed in the free market case, though centrally directed rather than the result of a multitude of individual decisions. Given that the planner is the only truly autonomous decision maker, there will be only a single determination that the plan is incompatible with the available resources rather than the mass panic that occurs when "all or nearly all businessmen find that their investments and estimates have been in error" (Rothbard [1962] 2004, ch. 11). Rather than running for the exits on their own, the local cadres will have to be instructed to do so. "The brake" as Kornai tells us, "is applied by central control," after which a period of austerity will be necessary until such time as the leadership is "reassured that tension has fallen, or even a measure of slack, an apparent underuse of resources, has appeared" (Kornai 1992, 190, 192). 
These socialist slowdowns will be no less prone to inefficiencies than the booms that precede them. Lacking the ability to determine whether or not specific activities make economic sense, the planner will have to use arbitrary criteria such as project size or industry type in determining which investments to halt. There will be no way to avoid throwing out the baby with the bathwater.

Just as in a free market economy, the fact that decision-makers have experienced one cycle does not mean that they will be able to avoid another. The details may be different the next time-novel investment rationales may be imagined, innovative technologies may be employed, new sectors may be involved. But as long as economic growth remains the priority, the fact that planning must be conducted in the absence of local knowledge guarantees that recurring rounds of malinvestment will be unavoidable.

Investment booms are not merely a possibility under central planning, but a logical inevitability. This conclusion follows from the following three premises:

(1) The planner's primary objective is economic growth, whether this be growth in an aggregate measure such as GDP or in output statistics for particular priority sectors.

(2) Local knowledge will be economically significant regardless of how the economy is organized.

(3) Plan fulfillment is the sole objective of the cadre on the spot.

Premise (3) means that the cadre on the spot will take advantage of the lacunae in the plan resulting from premise (2) to meet the planner's targets. And because (1) implies that future output increases will be targeted, it will be optimal for him to overinvest in roundabout production processes regardless of the resulting malinvestment at the macroeconomic level.

Busts are a logical inevitability as well if we add the following two additional premises:

(4) The macroeconomic effects of malinvestment must eventually become general knowledge.

(5) These effects will pose a threat to longer-term economic growth if left uncorrected.

These imply that the planner must at some point become aware of the intertemporal distortions resulting from the extensive growth 
strategy and introduce new policies to resolve them, thereby terminating the boom. Although the subjects may have "no opportunity to utter their dissatisfaction" and initially have to "eat less and bite their tongues," as Mises argued, this state of affairs will obviously have to end at some point before the entire population has starved to death.

\section{III.SOCIALIST ERROR CYCLES}

J. Guido Hülsmann (1998) presents an alternative approach to modeling business cycles based on what he refers to as an "essentialist" account of the errors in investment decision-making that drive them. He believes that conventional "consequentialist" stories are unsatisfactory because "as long as human beings choose, that is, as long as they are beings with free will, the correctness of choice must in principle be unrelated to preceding events and choices" (8). The problem with traditional Austrian business cycle theory $(\mathrm{ABCT})$ specifically, he argues, is that it is not generally valid to claim that increases in the money supply cause entrepreneurs to invest in projects that will later turn out to be unprofitable. There is no reason in principle why they could not foresee that these investments would fail and choose not to make them.

During a boom a significant number of people make the same mistake at the same time. Consequentialism explains this clustering of errors as the result of an event (e.g., a money supply increase) that leads decision-makers to err in some particular way. Hülsmann proposes that we instead take error as "the ultimate given." The question then becomes not "how does error come about?" but rather how can we explain the "repetitive occurrence of more or less synchronous errors of many persons." This requires identifying "more or less permanent patterns of action (institutions) in which the error of many persons is inherent." Such an institution must be built upon "a kind of error that is independent of time and place," which Hülsmann calls an "illusion" (1998, 8-9).

For Hülsmann, this institution is government, which he sees as founded on the illusion that society cannot function in the absence of the institutionalized violence of the state. The task for the theorist is then to "identify particular instances of government intervention and spell out precisely where the illusion is manifest." There will be 
"various specific error cycle theories (the economic aspect of which would be specific business cycle theories)" $(1998,14)$.

My argument in part II is consequentialist-error is caused by the planner's failure to access local knowledge, which results in the provision of malincentives to her subordinates. Note that this model differs from conventional $\mathrm{ABCT}$ in that the faulty decision-making is centralized. While in both explanations the malinvestments occur at the local level, these are only truly errors for the man on the spot. The cadre on the spot is a representative of the state, not an autonomous individual. His activity consists solely in carrying out instructions, using the resources at his disposal in a manner that is optimal for his plan-fulfillment objective. Ultimately it is the planner who errs by mistaking statistics for reality, thereby choosing means that must ultimately prove suboptimal for achieving her long-term goal of maintaining economic growth. This difference is a natural consequence of the cadre's relative lack of decision-making autonomy. Unlike his free market counterpart, he is not really at liberty to decide whether or not to invest. This decision is imposed on him by the logic of a system set in motion by a single authority acting in the name of the "people" as a collectivity rather than by the aggregation of decisions made by the individual citizens themselves via the market process.

On a more fundamental level, reformulating the story in essentialist terms reveals that the socialist cycle may be thought of as a particular instance of Hülsmann's general theory. If government is indeed an "illusory institution," under socialism, where economic life is entirely dominated by the state, recurring erroneous behavior will be unavoidable, though this behavior will be concentrated in the person of the planner, who is uniquely empowered to set the objectives for society as a whole. (Alternatively, we may think of Hülsmann's "synchronous errors of many persons" as being made by ideal cadres whose individuality has been entirely merged into a single collective "popular will" and therefore err collectively rather than individually.) And we may identify central planning as being "precisely where the illusion is manifest." Indeed, we can be even more certain that "it is not money but government intervention that accounts for the business cycle," as Hülsmann concludes, in a commonwealth where interest rates are not relevant to investment and money, at least in a theory, might not even exist at all. 
Mihai Macovei $(2015,433)$ finds that "the essentialist approach is useful, but lacks convincing arguments to become a general theory of business cycles". He challenges Hülsmann's claim to generality on two counts. First, a story premised on the idea that government is essentially a form of institutionalized aggression can easily be rejected by anyone who does not happen to share this view. Second, "except for the $\mathrm{ABCT}$, Hülsmann only mentions two other possible examples, such as the 'military-imperialistic' and the 'social security' cycle. He does not develop them further in order to explain their workings, which is a clear shortcoming in terms of expounding a theory that claims to be general and all-encompassing" $(2015,427)$. Furthermore, Macovei argues that even the "argumentation" underlying the essentialist reconstruction of the ABCT is "not irrefutable" $(2015,433)$.

Our consideration of the socialist business cycle, although not relevant to Macovei's specific objections to this argumentation, suggests possible counterarguments to his two more general points. It suggests, first of all, that the key characteristic of the state for the purposes of business cycle theory may be blindness rather than violence. This position is defensible given the obvious economic importance of local knowledge and the fact that planning is no less a part of any government's activity than coercion. In addition, one can point to the socialist cycle as an additional special case, thereby strengthening the assertion that the theory is "general and all-encompassing."

We may think of central planning as one specific instance in which the illusion of government, as Hülsmann characterizes it, is manifested, thereby arriving at a specific version of his general theory appropriate to the socialist commonwealth. But we may also restate this general theory by considering faith in governments' ability to plan, rather than belief in the necessity of state property rights violations, to be the illusion underlying government itself-not an unreasonable view given that the former must presumably precede the latter. The business cycle then becomes less a consequence of the expropriation of private property than of the state's inability to use what it has taken in an efficient manner. This restatement has the advantage of making the essentialist position easier to defend while leaving it basically intact. 


\section{CONCLUSION}

In Economic Calculation in the Socialist Commonwealth, Mises argues that without access to the local knowledge embedded in the price system, the socialist economic order will end up "floundering in the ocean of possible and conceivable economic combinations without the compass of economic calculation" (23). In the absence of any rational basis for decision-making, "the wheels will turn, but will run to no effect" (19).

Here, I have made a case for going beyond Mises's essentially static framework to explore his argument's dynamic implications. The planner may never see a complete picture of the economy, but what she does see can nevertheless be expected to vary over time. As a result, her mistakes will be serially correlated, leading to a pattern of alternating overinvestment and austerity not unlike a series of private sector manias and panics. Although the wheels will "run to no effect," they will run faster during some periods than others.

The incentive issues and political factors characteristic of real-world socialism complicate the story without changing its essential features. The main difference between our idealized commonwealth and existing socialist countries is that real cadres will find ways to influence the contents of the plan and strive to overachieve its goals (Winiecki 1988, Kornai 1992, Zhou 2004). Their priority is typically not plan fulfillment per se but advancing their own careers. But the basic problem - the diversion of resources from activities outside the planner's field of vision - will be the same, though exacerbated by cadres' attempts to game the system. The possibility of eliminating booms and busts through administrative reforms can also be ruled out. Central planning is inherently destabilizing.

It is straightforward to generalize Austrian business cycle theory to include both planned and market economies. In either setting, the essential features of the cycle are: (1) an expansionary impulse resulting in (2) a distorted signal of society's rate of time preference, followed by (3) malinvestment, (4) excess demand, and finally (5) contraction. Under socialism, we simply have the planner in the role of the banker, with the planner's economic growth policy replacing money supply increases as the expansionary impulse and unrealistically high output targets taking the place of below 
equilibrium interest rates as the distorter of the time preference signal. In either case, the result is malinvestment, while the excess demand may be manifested either directly, as physical shortages, or indirectly, as inflation. The final contraction will provide the same necessary readjustment whether it results from administratively imposed austerity or interest rate increases.

Far from being an impossibility, as many have imagined, the socialist business cycle may in fact be the state-driven business cycle par excellence. Without markets and private property, policy does not have to be transmitted indirectly to the private sector through a monetary or fiscal "transmission mechanism" nor are there any truly independent decision-makers. The state's economic management will have a direct and immediate impact and cannot fail to produce booms and busts under the five assumptions enumerated at the end of section II.

The socialist business cycle is also arguably the Hülsmannian error cycle par excellence. Where there are no private sector "animal spirits," the source of the "recurring erroneous behavior" is unambiguous. It can only be the state's blindness to the "particular circumstances of time and place," whether considered as a specific manifestation of the illusion of government or as this illusion's ultimate source.

\section{REFERENCES}

Bukharin, Nikolai, and Evgenii Preobrazhensky. [1920, trans. 1922] 2001. The ABC of Communism. HTML edition. Marxists Internet Archive. https:// www.marxists.org/archive/bukharin/works/1920/abc/index.htm.

Davies, Robert W. 1974. "Economic Planning in the USSR." Pp. 266-90 in Comparative Economic Systems: Models and Cases, ed. Morris Bornstein. Homewood, Ill.: Richard D. Irwin, Inc.

Demsetz, Harold. 1969. "Information and Efficiency: Another Viewpoint." Journal of Law and Economics 12, no. 1: 1-22.

DeWeaver, Mark A. 2012. Animal Spirits with Chinese Characteristics: Investment Booms and Busts in the World's Emerging Economic Giant. New York: Palgrave Macmillan. 
Eckstein, Alexander. 1976. China's Economic Development: The Interplay of Scarcity and Ideology. Ann Arbor, Mich.: University of Michigan Press.

Engels, Frederick. [1894] 1975. Anti-Duhring: Herr Eugen Duhring's Revolution in Science. Moscow: Progress Publishers.

Fan, Gang, and Xiaojing Zhang. 2004. Zenme you guo re le? Xin yilun jingji bodong yu hongguan tiaokong fenxi [Why Is There Overheating Yet Again? The New Round of Economic Fluctuation and an Analysis of Macroeconomic Adjustment]. Nanchang: Jiangxi People's Publishing House.

Fuller, Edward W. 2019. "Keynes and the Ethics of Socialism." Quarterly Journal of Austrian Economics 22, no. 2: 139-80.

Hayek, Friedrich. 1945. "The Use of Knowledge in Society." American Economic Review 35, no. 4: 519-30.

—. 1988. The Fatal Conceit: The Errors of Socialism. London: Routledge.

Huerta de Soto, Jesus. 2006. Money, Bank Credit, and Economic Cycles. Auburn, Ala.: Ludwig von Mises Institute.

Hülsmann, J. Guido. 1998. “Toward a General Theory of Error Cycles.” Quarterly Journal of Austrian Economics 1, no. 4: 1-23.

Keynes, John M. [1936] 1997. The General Theory of Employment, Interest, and Money. New York: Prometheus Books.

Kornai, Janos. 1992. The Socialist System: The Political Economy of Communism. Princeton, N.J.: Princeton University Press.

Lenin, Vladimir I. [1920.] n.d. "Report on the Work of the Council of People's Commissars." Address to the EighthAll-Russia Congress ofSoviets.Dec. 22,1920.SeventeenMomentsinSovietHistory (website).Accessed March 5, 2020. http://soviethistory.msu.edu/1921-2/electrification-campaign/ communism-is-soviet-power-electrification-of-the-whole-country/.

Lucas, Robert E. 1972. "Expectations and the Neutrality of Money." Journal of Economic Theory, no. 4, 103-24.

Macovei, Mihai. 2015. "The Austrian Business Cycle Theory: A Defense of Its General Validity." Quarterly Journal of Austrian Economics 18, no. 4: 409-35.

Mao, Zedong. [1959] 2004. "Examples of Dialectics." In Selected Works of Mao Tse-tung: Vol. VIII. Online version. Marxists.org. Marxists 
Internet Archive. http://www.marxists.org/reference/archive/mao/ selected-works/volume-8/mswv8_48.htm

Marx, Karl. [1863] n.d. Theories of Surplus-Value. Vol. 4 of Capital. Online version. [Marxists Internet Archive]. Marxists Internet Archive. Available at https://www.marxists.org/archive/marx/works/1863/ theories-surplus-value/.

_ [1887] 1999. Capital. Vol. I. The Process of Production of Capital. Online version. Marx/Engels Internet Archive. Marxists Internet Archive. https://www.marxists.org/archive/marx/works/download/pdf/Capital-Volume-I.pdf.

Matosich, Andrew J., and Bonnie K. Matosich. 1988. "Machine Building: Perestroika's Sputtering Engine." Soviet Economy 4, no. 2: 144-76.

McGregor, James. 2010. China's Drive for 'Indigenous Innovation': A Web of Industrial Policies. N.p.: US Chamber of Commerce.https://www. uschamber.com/sites/default/files/documents/files/100728chinareport_0_0.pdf

Mises, Ludwig von. [1920] 2012. Economic Calculation in the Socialist Commonwealth, trans. S. Adler. Reprint, Auburn, Ala.: Ludwig von Mises Institute.

- [1949] 1998. Human Action: A Treatise on Economics. Scholar's ed. Auburn, Ala.: Ludwig von Mises Institute.

People's Daily. 1959. "Quan guo yi pan qi" [The Whole Country as a Chess Game]. Feb. 24, 1959: 1-2.

Rothbard, Murray N. [1962, 1970] 2004. Man, Economy, and State with Power and Market. Scholar's ed. Auburn, Ala.: Ludwig von Mises Institute.

Samuelson, Paul A. 1939. "Interactions Between the Multiplier Analysis and the Principle of Acceleration." Review of Economic Studies 12, no. 2: 75-78.

Scott, James C. 1998. Seeing like a State: How Certain Schemes to Improve the Human Condition Have Failed. New Haven, Conn.: Yale University Press.

Snow, Edgar. 1968. Red Star over China. New York: Grove Press.

Tikhanov, Nikolai A. 1981. Guidelines for the Economic and Social Development of the USSR for 1981-1985 and for the Period Ending In 1990. Moscow: Novosti Press Publishing House. 
Wang, Jian. 2008. "Zhongguo gaige kaifang sanshi nian hongguan tiaokong huigu" [A Review of Thirty Years of Chinese Macroeconomic Adjustment Under Reform and Opening]. Pp. 1-15 in Zhongguo hongguan tiaokong sanshi nian [Thirty Years of Macro-economic Adjustment in China], ed. Wei Kang. Beijing: Economic Science Press.

Wellisz, Stanislaw. 1964. The Economies of the Soviet Bloc: A Study of Decision Making and Resource Allocation. New York: McGraw Hill Book Company.

Winiecki, Jan. 1988. The Distorted World of Soviet Type Economies. Pittsburgh, Pa.: University of Pittsburgh Press.

Wu, Jinglian, and Guochuan Ma. 2016. Whither China: Restarting the Reform Agenda. New York: Oxford University Press.

Zauberman, Alfred. 1964. Industrial Progress in Poland, Czechoslovakia, and East Germany: 1937-1962. London: Oxford University Press.

Zhou, Li'an. 2004. "Jinsheng boyi zhong zhengfu guanyuan de jili yu hezuo" [Cooperation and Government Officials' Incentives in Promotion Competitions]. Jingji yanjiu [Economic Research] 6: 33-40. 